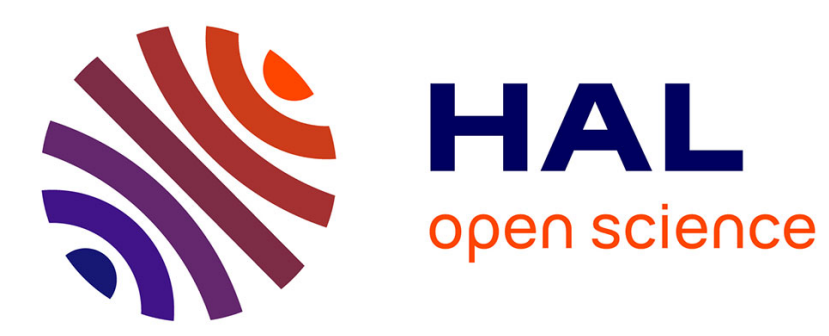

\title{
Greek-Cypriot Teachers' Constructions of Turkish-speaking Children's Identities: Critical Race Theory and Education in a Conflict-ridden Society
}

Michalinos Zembylas

\section{- To cite this version:}

Michalinos Zembylas. Greek-Cypriot Teachers' Constructions of Turkish-speaking Children's Identities: Critical Race Theory and Education in a Conflict-ridden Society. Ethnic and Racial Studies, 2010, PP (PP), pp.1372-1391. 10.1080/01419871003678999 . hal-00580695

\section{HAL Id: hal-00580695 \\ https://hal.science/hal-00580695}

Submitted on 29 Mar 2011

HAL is a multi-disciplinary open access archive for the deposit and dissemination of scientific research documents, whether they are published or not. The documents may come from teaching and research institutions in France or abroad, or from public or private research centers.
L'archive ouverte pluridisciplinaire HAL, est destinée au dépôt et à la diffusion de documents scientifiques de niveau recherche, publiés ou non, émanant des établissements d'enseignement et de recherche français ou étrangers, des laboratoires publics ou privés. 


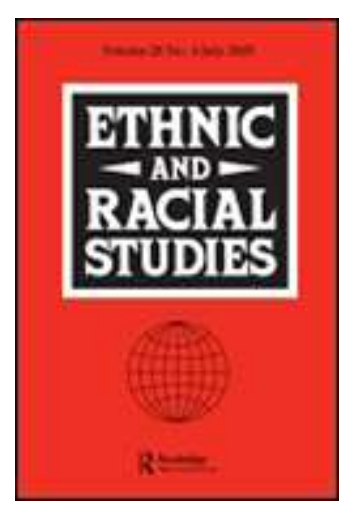

\section{Greek-Cypriot Teachers' Constructions of Turkish-speaking Children's Identities: Critical Race Theory and Education in a Conflict-ridden Society}

\begin{tabular}{|r|l|}
\hline Journal: & Ethnic and Racial Studies \\
\hline Manuscript ID: & RERS-2009-0138.R3 \\
\hline Manuscript Type: & Original Manuscript \\
\hline Keywords: & $\begin{array}{l}\text { Racism, Nationalism, Education, Ethnic Conflict, Multiculturalism, } \\
\text { Ethnography }\end{array}$ \\
\hline \multicolumn{2}{|l}{} \\
\hline
\end{tabular}

\section{S) ScholaroNe \\ Manuscript Central}




\title{
Greek-Cypriot teachers' constructions of Turkish-speaking children's identities: Critical race theory and education in a conflict-
} ridden society

\author{
Michalinos Zembylas
}

\begin{abstract}
This article examines Greek-Cypriot teachers' constructions of Turkish-speaking children's identities in the Greek-Cypriot educational system. Drawing on interviews and classroom observations from a two-year ethnographic study conducted in three primary schools in the Republic of Cyprus, the author explores how Turkish-speaking children enrolled in these schools are racialised, ethnicised and classed within the dominant discourse of Greek-Cypriot teachers. The article discusses how the homogenised perceptions expressed by the majority of participating teachers in this study are illustrative of structural racism that reinforces these constructions in teaching practices. Yet at the same time, resistance is present in the discourse and practice of a few teachers; this resistance is expressed through a counterpositioning of the 'normal/ised' identities of Turkish-speaking children. The author argues that without structural transformation, the fact and practice of racism/nationalism/classism will go unaltered in schools.
\end{abstract}

Keywords: Racism; Cyprus, schools; identity; ethnography; resistance.

\section{Introduction}

From and the 1970s onward, a substantial number of studies in different educational settings have shown that teachers hold negative stereotypes and low expectations of racial/ethnic minoritised children. The literature relating to (negative) teacher expectations and constructions of children from minoritised ethnic/racial backgrounds shows that these stereotypical representations are mapped onto educational policy and everyday teaching practices (Archer and Francis 2005). In his recent review of research in England during the last three decades, Stevens (2007) asserts that an investigation on the racialised, ethnicised and classed constructions expressed by teachers should not focus on whether teachers or specific school processes are racist 
or discriminating as such, but could explore 'the contextual development and activation of these phenomena' (p. 173, added emphasis).

In response to the call for research on the contextual development of school processes that may be racist or discriminating, this article examines Greek-Cypriot teachers' constructions of Turkish-speaking ${ }^{1}$ children's identities in the Greek-Cypriot educational system through the theoretical lens of Critical Race Theory (CRT). Cyprus remains a deeply divided (and segregated) society due to the protracted nature of the historical conflict between the two larger communities on the island, that is, the Greek Cypriots and the Turkish Cypriots. The long history of this conflict, the ongoing division of the island since the 1974 Turkish invasion, the partial lift of restrictions in movement in 2003, increased immigration, and the issues of EU membership for Turkey are some of the contextual matters that need to be considered in exploring the development of 'racist' or 'discriminating' school practices in Cyprus. Being a Greek-Cypriot researcher and educator who has been educated in a nationalistic educational system (see Zembylas and Karahasan 2006), I am interested in examining how majoritised teachers' constructions of minoritised otherness are racialised and what consequences they have. This research is important because examining teachers' views will make us (i.e. educators, teachers, policymakers, researchers) more knowledgeable about how to prepare anti-racist teacher education programs and policies that take into consideration all teacher views without diminishing, dismissing or over-valuing them. A rich academic agenda exists towards this end, emphasizing the significance of considering teachers' views in the formulation of anti-racist education (Gillborn 2008).

This article focuses on the racialised, ethnicised and classed constructions of Turkish-speaking children within Greek-Cypriot teachers' discourses. In this context, 
the following questions are examined: (1) How do Greek-Cypriot teachers perceive the race, ethnicity and class of their Turkish-speaking students, and how does the CRT concept of the structural racialisation of minoritised groups illuminates these teachers' constructions of Turkish-speaking children's identities within the GreekCypriot educational system? and (2) If teachers' views are racialised/ethnicised/classed, are there any pockets of 'resistance' (Youdell 2006) to the 'normal/ised' identities ascribed to Turkish-speaking children, and if so, how are these resistances manifest in school life?

\section{Critical race theory and teachers' constructions of minoritised children}

\section{Critical race theory}

Critical Race Theory has its origins in US legal scholarship but is increasingly used by educators around the world (such as the UK, Europe and Australasia) to analyse the continued salience of structural racism in educational settings (Gillborn 2008). According to Delgado and Stefancic (2001), there are six unifying tenets that define the movement of CRT: (1) racism is ordinary; (2) the current system of White-overcolour ascendancy serves important purposes; (3) race and races are products of social thought and relations; (4) the dominant society racialises different minority groups at different times; (5) intersectionality and antiessentialism are present, whereas everyone has overlapping, conflicting identities and loyalties; and (6) there is shared minority experience that people of colour communicate about race and racism that White people are unlikely to know is present. Central to these tenets is the notion that racism is pervasive and systemic, not merely an individual pathology. Racism is ingrained in everyday practices, events, institutional policy rules and administrative 
procedures in subtle and often unnoticed ways, yet the actions associated with everyday racism are seen as derogatory by persons of colour. Critical Race Theory, then, calls attention to the existence of structures in the broader society that are created and maintained through institutions, relationships and practices.

Throughout this article, the majoritised (i.e. Greek-Cypriot) teachers' perceptions of the minoritised (i.e. Turkish-speaking) children are theoretically framed within CRT. Critical Race Theory is appropriate for the case of Cyprus because it offers insights and methodological tools to identify and analyze existing evidence of the structural and cultural aspects that maintain dominant racial positions (coupled with ethnic ones) in and out of schools (Spyrou 2009; Trimikliniotis 2004; Zembylas 2008). The ethnopolitical conflict in Cyprus is very much related to race, in other words, because existing evidence highlights how the ethnic Other is also viewed through racial lenses. According to this research, teachers' racialised/ethnicised/ classed constructions inform and reflect the larger (unjust) structures in the GreekCypriot educational system, indicating how the Greek-Cypriot educational system performs exclusion. Although the implementation of CRT in an American, European or other context would look different than its use in the Greek-Cypriot educational system, there is an important commonality: the challenge of racist practices through investigating the lived experience of minoritised peoples as a defence against universalistic discourses (Gillborn 2008; Taylor, Gillborn and Ladson-Billings 2009).

Although a number of conceptual and methodological tools have grown out of CRT (e.g. whiteness as property, interest convergence), I draw specifically on two ideas that are used in this article: (1) the concept of how the dominant society racialises minoritised groups in different ways, and (2) the theme of resistance, that is, how some narratives constitute counter-storytelling that aim to upset hegemonic 
truth. First, CRT is particularly helpful in analyzing how majoritised teachers' racialised/ethnicised/classed constructions are manifest in everyday school practices that perpetuate the uncritical use of race and other categorizations (Taylor, Gillborn and Ladson-Billings 2009). By arguing that racism is endemic in both institutional structures and everyday 'business-as-usual', CRT helps analyze the ways in which majoritised teachers' constructions about minoritised students' identities constitute racialised, ethnicised and classed perceptions. Second, the theme of resistance (e.g. through counter-storytelling) refers to challenging myths, assumptions and received wisdoms grounded in colour-blind ideologies and discourses of objectivity and neutrality (Gillborn 2008; Youdell 2006). Thus CRT questions liberal views that are deeply embedded in education and society, exposing the racist inequities 'that are created and sustained behind an inclusive and progressive façade' (Gillborn 2008, p. 28).

\section{Teachers' constructions of minoritised children's identities}

The literature in many countries around the world shows that majoritised teachers perceive minoritised children 'differently'. A full exploration of teacher racism all over the world is beyond the scope of this article; however, a brief review of some research evidence is valuable: (a) in understanding how teachers perceive minoritised children's identities in other parts of the world—including conflict-ridden areas-and, (b) in appreciating the implications of these perceptions in teachers' practices.

Studies in England indicate the prevalence of racism in schools, mainly in terms of teachers' (un)intended attitudes, behaviours and practices (Gillborn and Mirza 2000; Gillborn 2008). In particular, it has been found that teachers treat Black, Muslim and Asian students in stereotypic or hostile ways and assume that these 
students have behaviour problems (e.g. Archer 2003; Connolly 1998); teachers' constructions are found to be grounded in racialised, gendered and classed assumptions (e.g. Archer and Francis 2005). Similarly, research in other European countries (e.g. Belgium and the Netherlands) shows how Belgian teachers discriminate against Turkish children (e.g. Stevens 2008), or Dutch teachers disregard Moroccan children (e.g. de Haan and Elbers 2004). Also, research in the United States shows that teachers' negative stereotypes and low expectations of minoritised children partly explains the overrepresentation of culturally and linguistically diverse students in special education programmes, which, in turn, affects the eventual educational outcomes of these children (e.g. Harry and Klinger 2006). All these representations of minoritised children are grounded in homogeneous perceptions of identity and colourblind perspectives and place the burden for adaptation to the majoritised norms on minoritised children (Phoenix 2002; Stevens 2007). Most of these studies argue that teachers are de facto running racist regimes in their classrooms either without realising it, or meaning to, or while they deny it to researchers (i.e. speech and practice are different).

Research on race and ethnicity in England, other European countries, the US and so on has parallels in conflict-ridden areas such as Northern Ireland and Israel. In particular, it has been found that teachers tend to homogenize minoritised children and disregard them without realizing it, even in integrated settings (e.g. see Bekerman and Maoz 2005; Donnelly 2004). However, there is evidence that the politics of conflict adds to the complexity of the situation in that issues of in-group/out-group classification and hierarchy become more intense (see McGlynn, Zembylas, Bekerman and Gallagher 2009). Similar evidence on the entanglement of issues of race and ethnicity also exists in the Cyprus conflict, as already noted earlier 
(Zembylas 2008). In general, studies from conflict-ridden areas indicate that racialised, coupled with ethnicised discourses operate through processes of classification and hierarchy, differentiation and homogenisation, exclusion and entitlement (Bekerman, Zembylas and McGlynn 2009). These findings confirm anthropological and sociological findings in other disciplines that ethnic, racial and class identities, too, are social and cultural constructions, not biologically determined (Jenkins 1996; Woodward 2002). These ideas emphasize that ethnicity and other identity constructions are neither static nor monolithic; rather, they are shifting, plural, fluid, relational, constantly negotiated and embedded within power relations. Recognising the idea that children have a range of identities, with different ones acquiring salience in different contexts, can be useful in understanding how particular social positions_-for example, race, class, ethnicity—are ascribed to children through discursive formations and ideologies such as racist talk and discriminatory practices (Phoenix 1998; Ross 2007).

Little, if any research, has examined Greek-Cypriot teachers' constructions of Turkish-speaking children's identities in the Greek-Cypriot educational system. Turkish-speaking children occupy an interesting position in the Greek-Cypriot educational system; Turkish Cypriots and/or Turks are generally represented in extremely negative ways as a result of the historical conflict between Greeks and Turks (Spyrou 2006). This article analyses, then, how Greek-Cypriot teachers perceive the race, ethnicity and class of their Turkish-speaking students, and what the implications of these perceptions are in teachers' practices.

\section{The study}


The data reported in this article are drawn from a two-year ethnographic study (20072008) in three primary schools in the Greek-Cypriot educational system, examining multicultural education and particularly the pedagogical practices, constructions of otherness and relations between the majoritised group (i.e. Greek Cypriots) and the minoritised Turkish-speaking children. The uniqueness of this study is that these three primary schools belong to a very small number of schools in the Republic of Cyprus in which Turkish-speaking students are enrolled; Greek Cypriots and Turkish Cypriots have always been educated in segregated educational systems. Issues surrounding race, ethnicity and class are central in this analysis. But before providing further details on the participating schools and the research design it is valuable to provide some further information on the socio-political context of the study.

\section{The socio-political context of the study}

Cyprus emerged as an independent state in 1960 after a Greek-Cypriot struggle against British colonial rule. This anti-colonial rebellion of the Greek Cypriots (80\% of the population), however, did not aim toward independence but enosis, union with Greece. At the same time, Turkish Cypriots, the largest minority on the island (18\%), aimed at taksim, ethnic partition. Past issues such as the Ottoman occupation of Greece and Cyprus and the recent traumas of ethnic division - first in the 1960s when the Turkish Cypriots were the main victims, and then in 1974 when Turkey invaded and divided the island, displacing many thousands of Greek Cypriots and Turkish Cypriots - came to signify an intractable conflict in the region. The Turkish invasion of 1974 separated the two communities-Greek Cypriots reside in the south and Turkish Cypriots in the north. Despite numerous diplomatic efforts and the partial lift of restrictions in movement across the dividing line in 2003, the partition of Cyprus 
remains. The Republic of Cyprus became a full EU member in May 2004, while Turkey applied to become an EU member. Recent debates around issues of EU membership for Turkey further complicate the relations between Greek Cypriots and Turkish Cypriots: arguments from the Greek-Cypriot side emphasize that Turkey cannot become an EU member, unless it ends the division of Cyprus, while arguments from the Turkish-Cypriot side highlight that Turkey needs to continue having guarantor powers over Cyprus².

Greek-Cypriot and Turkish-Cypriot children have always been educated separately. Currently, Greek Cypriots attend schools in the south and Turkish Cypriots in the north. In the south, however, 'multicultural' schools, attended by children from various cultures, including children whose parents are migrant workers or are married to someone from another culture, have emerged. Occasionally, Turkish-speaking children (i.e. Turkish Cypriots and Roma), whose parents stayed in the south after the war of 1974 or moved there recently, enrol in these schools. Although in the south policy documents and official curricula include strong statements about humanistic ideas and respect for human rights, justice, and peace, in practice non-Greek Cypriot children are seen as deficient and needing to be assimilated (Panayiotopoulos and Nicolaidou 2007; Zembylas in press). Various studies also demonstrate that school textbooks and national rituals, symbols, and celebrations systematically create dehumanized images of the Turks and Turkish Cypriots (Bryant 2004; Zembylas 2008).

The current model of intercultural education being implemented in the GreekCypriot educational system is a mainstreaming programme in which language learners attend classrooms with Greek-speaking children (the majority). This model has developed in response to recent immigration in Cyprus. There are a number of schools 
that become part of a Zone of Educational Priority (ZEP). ZEP networks have schools with high numbers of non-Greek Cypriot students but this is not the rule; there are a number of other schools in the Greek-Cypriot educational system with high numbers of non-Greek Cypriot students that are not in a ZEP network. ZEP schools receive additional help—such as extra hours for assisting non-indigenous students to learn the language. Research also shows that Greek-Cypriot teachers are ill prepared to deal with the challenge of multicultural education (Panayiotopoulos and Nicolaidou 2007; Trimikliniotis 2004; Zembylas and Iasonos in press) that becomes even more complicated in schools where Turkish-speaking children are enrolled. Although there are a few such schools in the south and the Turkish-speaking student population in those schools is small (usually between 5-10\% except in one case in which it rises to $1 / 3$ of the student body), the situation is complex in light of the unresolved political problem.

\section{Participating schools}

The research reported here used a multiple case-design, in which each of the three primary schools constituted a unit of analysis (Merriam 1998). The choice of these schools (which became multicultural only in the last few years) was based on the presence of Turkish-speaking children in the student population. The majority of Turkish-speaking children did not speak or understand any Greek. Also, there was regular migration between the south and the north part of Cyprus among Turkishspeaking students, thus influencing their education and school participation. Free meals were provided to these students in all three schools, but no lessons or extra language classes were conducted in the children's mother tongue (except in one of the schools - the one with the highest percentage of Turkish-speaking children). These 
schools were: the Hill School, the Town School, and the Sea School ${ }^{3}$; the first and the third school were part of a ZEP network.

The Hill School (HS) is a pseudonym for a primary school located in a small city and has 16 teachers (all Greek Cypriots) and 140 students of which $70 \%$ are Greek Cypriots, $12 \%$ Turkish-speaking students, and 18\% students from various other countries. The socio-economic background of students is considered low and the Greek-Cypriot population is mainly comprised of refugees who fled from the north to save their lives in the aftermath of the Turkish invasion in 1974.

The Town School (TS) is a pseudonym for a primary school located in a small town; it has 12 teachers (all Greek Cypriots) and 330 students from which $21 \%$ are non-Greek Cypriot students (they come from different cultural backgrounds) and $8 \%$ are Turkish-speaking students.

Finally, the Sea School (SS) is a pseudonym for a primary school located in a fairly large city (by Cypriot standards) and has 12 teachers (10 Greek Cypriots and two Turkish Cypriots who are responsible for the teaching of Turkish to Turkishspeaking students). Greek lessons are also offered to Turkish-Cypriot parents in the afternoon; a theatre group, consisting of Greek-Cypriot and Turkish-speaking parents, has also been formed. The Sea School has 139 students from which 37\% are Turkishspeaking, 50\% are Greek-Cypriots, and the rest from various cultural backgrounds. The socio-economic background of most students is considered low.

\section{Data collection and analysis}

This study draws on critical ethnographic methodologies (Carspeckem and Walford 2001; Madison 2005); insights from critical ethnographic methodologies are used to look for teacher discourses and practices with the purpose of exposing and critiquing 
processes of injustice and unfairness. These insights, in conjunction with the use of CRT, are valuable for two reasons: first, they help pay attention to the ways in which individual practices are linked to larger social processes that are unjust or unfair to minoritised children; second, the notion that racism is not an individual pathology is asserted and the cultural system that tolerates racist practices (or occasionally resists to those) is exposed.

The data collection methods included interviewing, ethnographic observations for eight consecutive weeks in each school (from 7:30 am to 1:05 pm, that is for the duration of the school day), and collection of documents (curriculum and policy documents, school demographic information, teaching materials and children's work). Semi-structured interviews were conducted with a total of 3 school principals, 18 teachers, and 60 children (aged 7-12). This article examines data collected in semistructured interviews with 18 teachers (12 women and 6 men) and 3 principals (two women and one man), all Greek Cypriots. All interviews were conducted by the author and/or a research assistant and were tape-recorded and transcribed in Greek; all necessary quotes were translated for this article, which deals only with teachers' perceptions about Turkish-speaking children. Teachers and principals were asked questions about a range of issues including their feelings and aspirations of Turkishspeaking children, their views on the achievement of these children at school, the ways that the school and the educational system treats these children, and generally how Turkish-speaking children learn and interact with other children. Ethnographic observations were recorded by the research assistant in field notes and focused on the ways that Greek-Cypriot teachers and students interacted with Turkish-speaking children in the classroom, the schoolyard and the staffroom. The possible bias this process might occasion was counterbalanced by cross-analysis of the data conducted 
by an external evaluator who checked our interpretations. The data sources also included documents of student work and teachers' planning related to various aspects of their teaching.

To ensure validity, the research assistant and I worked separately and collaboratively to analyse the data, using an interpretive method of coding (Erickson 1986) to ascertain confirming and disconfirming evidence of assertions arising from our data sources. We independently read and coded the data following the opencoding techniques outlined by Strauss and Corbin (1994). Building on this analysis, we interpreted the data by developing themes, categories and tentative hypotheses. First, the analysis was undertaken both per teacher respondent and per school (withincase analysis). Second, a comparative analysis between the schools (cross-case analysis) was completed.

The following pages examine a range of interview excerpts highlighting the Greek-Cypriot teachers' constructions of Turkish-speaking students' identities. First, I explore data exposing the racialised, ethnicised and classed perceptions of the majority of Greek-Cypriot teachers who participated in this study, showing how their perceptions are linked to larger structural, systemic issues of race, ethnicity and education. Second, I highlight the resistance that is present in the discourse and enacted curriculum of a few teachers. I close with a discussion of the implications of the racialised, ethnicised and classed constructions expressed by teachers in terms of resisting structural racism and enacting alternative pedagogical practices.

The racialised, ethnicised and classed perceptions of Greek-Cypriot teachers about Turkish-speaking children's identities 
The majority of Greek-Cypriot teachers (13 of the 18) in the three participating schools classified Turkish-speaking children according to racial, ethnic and class categories. One typical understanding of Turkish-speaking children is captured in the conversation that follows. During this conversation, a female teacher at Hill School discussed the cultural characteristics of Turkish-speaking students, explaining why they were not accepted by the majority of Greek-Cypriot students ${ }^{4}$ :

Teacher: First of all, Turkish-speaking students are distinguished by their external appearance. They have a darker skin complexion, they are extremely dirty and untidy, especially the Roma, and they don't speak any Greek. They usually stink and this is a cultural thing. Anyway, they don't have the habit of cleaning themselves and so our children [Greek Cypriots] don't like to play or sit in class with them. [...] And there is, of course, the hostility against the Turks.

Researcher: What do you mean by that?

Teacher: I refer to these children's Turkish identity and the fact that Turks are our historical enemies.

Researcher: How does this influence you as a teacher?

Teacher: It gives you an awry feeling... I mean they are children but they are also of Turkish origin. It's impossible to get this out of your mind.

In this short exchange, this teacher identified almost all the issues raised by most teachers when they referred to Turkish-speaking students. She talked about Turkish-speaking children being poor, dark-coloured, unclean, and of different ethnic origin and argued that the sensitivity about these issues was further accentuated as a 
result of the historical conflict with the Turks. Importantly, these issues were used to justify the rejection of Turkish-speaking children; however, the burden of rejection was placed on minoritised children. Yet, the majority of the teachers we interviewed admitted that Turkish-Cypriot children were not yet fully accepted. 'They are becoming more and more accepted, but their ethnic origin always sticks out,' said the principal at Town School, and added: 'They have a Turkish origin, you know... with the occupation of our country, this influences our feelings about them. They come here and they have all these benefits from the government. We don't like that.' Several teachers in all three primary schools referred to the financial aid that Turkishspeaking families received from the government and expressed resentment for this. 'I am sorry but this makes me very angry,' said one male teacher at Sea School and continued: 'I know how it's going to sound but I'll say this anyway. They [Turkishspeaking families] come here and go to the occupied areas [the north] whenever they like, they are extremely poor and uncivilised, and yet they receive more financial aid than our [Greek-Cypriot] poor families. This is not fair.'

Many teachers in all three schools talked openly and freely about the language and culture 'deficiency' of Turkish-speaking children. As a female teacher at Hill School admitted:

\footnotetext{
We do everything possible to help these children learn the language and become a bit more civilised because they have no manners from home. But no matter what we do, these children are incapable of learning the Greek language. [...] We are pressured to show that Greek-Cypriot children are not left behind as a result of the low level at which Turkish-speaking students are permanently.
} 
The Turkish-speaking students' difficulties to participate in class activities were obvious through our ethnographic observations. For example, we were present in several incidents in which the teacher was simply teaching to the rest of the class, ignoring the Turkish-speaking students who did not do anything or simply drew pictures on their notebook. When asked to comment why Turkish-speaking students seemed to be ignored, one (male) teacher at Town School explained:

\begin{abstract}
Look... I stopped insisting on having them sit next to our children or putting a lot of pressure on them. It's impossible to include these children as long as they don't learn to speak Greek. They got the message, OK it's our fault too, but they got the message that, "I am here just to be and whether I do something or not, whether I can do something or not, nobody will pay attention to me." This is a common secret among us, so I don't have too many expectations from them.
\end{abstract}

Most teachers denied the existence of discriminatory and racist perceptions or practices—either systemic or solely individual—against Turkish-speaking children. More importantly, embedded in these assumptions about the absence of any racial discrimination in the three schools was a belief that the majoritised group (i.e. Greek Cypriots) had the right to determine 'the rules of the game' and even be 'racist.' As one female teacher at the Hill School asserted, 'We do everything possible to be fair. But it's their [Turkish-speaking children's] responsibility to learn the rules of the game and adapt to our way of life. Why should we change for them?' Another (male) teacher at Town School put this more bluntly: 'Look, given the threat we face to 
become extinct as Greeks, I think we are justified to be a bit racist. It's a matter of survival.' In general, these teachers failed to recognize the systemic, structural component of the Greek-Cypriot privilege in the Greek-Cypriot educational system and its unequal implications for Turkish-speaking children. Instead, these teachers were free to express their decidedly racist views under the cover of the 'threat' of extinction as a (Greek) community.

At the same time, however, most teachers (regardless of school) claimed that Turkish-speaking students were mostly integrated in Greek-Cypriot schools without major problems. These claims, in conjunction with the 'racist' assertions identified earlier, indicated that there were conflictual or ambivalent discourses 'within' individual teachers. Consider, for example, the following two interview excerpts by the same teacher at the Sea School:

The most important thing is to treat all children equally. When you have a conflict, for example, between Greek Cypriots and Turkish Cypriots, you don't approach the incident as a problem between two ethnic groups. You don't make distinctions between them on the basis of their ethnic or cultural origin.

To tell you the truth, Turkish Cypriots are the most disruptive and unfocused children in the whole school. They always find ways to avoid learning and engage in misbehaviour. [...] Our children are polite, diligent, attentive and clean. They are completely the opposite from Turkish Cypriots. [...] The Turkish-Cypriot families are poor and don't really care about their children's 
education; unavoidably, this lack of interest passes on to the children themselves.

Like teachers in the other two schools, this teacher delineated between two types of students on the basis of their origin. Greek Cypriot students were 'normal'-well behaved, diligent, and polite-while Turkish-speaking students were aggressive, unclean, poor and did not care about their education. However, this normalisation seemed to be grounded in a 'colour-blind' and 'equality for all' rhetoric. In other words, there was a mixing of claims about the educational system being objective, equal and colour-blind with perceptions that Turkish-speaking students misbehaved, were poor and somehow deficient. The majority of teachers brought the issue of 'low socioeconomic status' and 'being dirty' as characteristics of Turkish-speaking students; therefore, to some extent there was evidence that the 'racism' of teachers involved class issues, too.

\section{Resistances in the discourse and enacted curriculum of some teachers}

In this section, I highlight some of the resistances enacted through the teaching practices of five teachers and the leadership of one of the principals in the three participating schools. Although the racialised, ethnicised and classed constructions are difficult to change, unravelling resistances to 'normal/ised' teachers' perceptions creates openings (e.g. see Gillborn 2008; Youdell 2006) for alternative constructions of Turkish-speaking children's identities. Some of the resistances in the discourse and practice of these teachers are discussed below.

First, it is important to acknowledge how the principal at Sea School assumed at activist role in the community and engaged in practices that struggled to create a 
school culture grounded in social justice and anti-racism. For example, this principal referred to the importance of being committed to social justice values and beliefs that aimed at changing school structures and practices that 'are unfair to some students.' His vision was 'to create a school that works in a just way... so that student outcomes are not related to students' ethnic or cultural background, colour, language, or race. I want my school to be successful for all students.' Discussions with this principal highlighted the negative implications of teachers' racialised, ethnicised and classed constructions, referring specifically to the marginalization of Turkish-speaking children. He also emphasised that it was his 'moral duty' to engage in challenging stereotyped perceptions, no matter where they came from.

Furthermore, the principal at Sea School took a clear stance against discourses and teaching practices that were discriminating towards Turkish-speaking children. Just like CRT theorists point out, this principal highlighted that racism, nationalism (especially in Cyprus) and classism 'were not problems of individuals but of societies' and that stereotyped perceptions were constructed to maintain the privilege of the hegemonic group (i.e. Greek Cypriots). Clearly, the majority of teachers we interviewed defended themselves as not being implicated in racism/nationalism/ classism, yet this principal insisted that teachers' stereotyped perceptions were present. Thus he challenged his teachers on every opportunity (e.g. staff meetings, breaks, one-to-one basis) and encouraged them to consider: 'Why is it that Turkishspeaking children are always framed as failures and then eventually fulfil these expectations?' Or, 'What are the consequences of rendering Turkish-speaking students as “misbehaved” or “backward”?' As he further explained: 
My school staff and the parents need to be convinced first that it is morally unacceptable to subscribe to deficit thinking for minority students or students who come from low socio-economic background. It's not the students' fault but the system's failure that sustains the disappointing outcomes for these students. Naturally, there is a lot of resistance. [...] Non-indigenous students are blamed essentially for everything that happens at the school. [...] So, I encourage my staff to attend workshops, conferences and seminars and bring back specific ideas with which they can change how we deal with these issues.

Another example of resistance was found at Town School. A teacher expressed repeatedly her public disagreement at the ways her colleagues treated Turkish-speaking children. As she explained in an interview:

\begin{abstract}
Non-native children want attention and in this school they don't get it. Here the situation is "cool" for everyone. The culture is very Greek Cypriot... The teachers don't talk to Turkish-speaking children with respect. This situation stigmatizes Turkish-speaking children and the stereotypes are perpetuated among all children. [...] I don't hesitate to tell you that there is a lot of racism here. [...] Children say things like "If you are touched by Melike you will get sick". This is blunt racism! And some teachers and the principal herself are in front of such incidents and they just laugh.
\end{abstract}

This teacher also emphasized that discourses about fairness and neutrality were essentially rhetorical ways of covering discrimination. Her efforts to resist racialised, ethnicised and classed perceptions turned the majority of her colleagues against her. 
The truth is that we [teachers] often discuss about Turkish-speaking students, not because we care about them but because they create problems. This is the truth, in all honesty. I don't ever remember a colleague expressing concerns about these children, coming up with ideas and things to do to help them and include them in the school community. Usually, the discussion is about what "this Turkish-Cypriot student did to me today," and things like that. At a teachers' meeting, I dared once to say that these children were justified to behave the way they did because they knew they were not welcomed here and that we resented their presence. I was fiercely attacked by several colleagues who said I had a "Turkish-friendly" attitude.

When it was discovered (with the help of this teacher) that the school administration at Town School did not allocate the proper number of hours for the support of Turkish-speaking students to learn Greek and receive help based on the existing government policy, we asked the principal to explain her decision. The principal was visibly distressed:

Look, I think it's fairer to our children [Greek Cypriots] as well to take some hours from the support allocated to Turkish-speaking students. Besides, we were told to allocate these hours the way we think it's right. I considered it fairer to do it in this way because I think it's unfair to give all the periods to non-native students and give nothing to Greek-Cypriot children. 
Finally, another teacher at Hill School resisted the 'normalization' of Turkishspeaking children by sharing with colleagues her experiences from providing individualised instruction to these children in pull-out sessions. As she pointed out in an interview:

Turkish-speaking children are totally different when they are by themselves. In the regular classroom, they seem isolated and scared and do not participate in discussions, because they don't feel comfortable with their knowledge of Greek. When they are by themselves in these supportive instructions, they are happy, expressive and alive. [...] I try to communicate this to my colleagues but $[\ldots]$ they don't believe that these children have the potential to learn, if you show them love and respect.

Teacher resistance, although isolated and small, attempted to provide alternative constructions about Turkish-speaking children's identities through highlighting the problematic features of fixing these children to particular static descriptions. The positioning and counter-positioning of Turkish-speaking children's identities contained important implications for these children's survival and success in the Greek-Cypriot educational system. The dominant discourse of racialised, ethnicised and classed perceptions about Turkish-speaking children and the normalization of these children's identities showed how the dominant group racialised this particular minoritised group. The teachers and the principal who resisted this dominant discourse were critical of racialised, ethnicised and classed perceptions and the mechanisms through which such perceptions occurred in systemic ways. By applying a counter-construction of Turkish-speaking children's identities, an 
oppositional praxis was enacted and turned the 'normal' identities of these children into contested spaces, even in minor ways.

\section{Implications and conclusion}

There are two key findings in this study; the first has to do with how Greek-Cypriot teachers perceive Turkish-speaking children, and the second highlights the openings that are manifest through teacher resistance. First, it is shown that Greek-Cypriot teachers perceive Turkish-speaking children in racialised, ethnicised and classed ways, and the socio-political structures in Cyprus influence teachers' negative discourses and practices toward these children. Most of the classic studies on teacher racism suggest that teachers are running racist regimes in their classrooms either without realising it, or meaning to, or while they deny it to researchers. The remarkable finding in this study is that several teachers say they are racist, claiming that they are justified to act in these ways in light of the political situation in Cyprus; in other words, there is not a 'mismatch' between spoken account and actual practice. Teachers' perceptions, then, entail a sense of 'right' to be racist, because this 'right' is perceived as a defence mechanism against Turkish efforts to dominate all over Cyprus and change its demographic character (Zembylas 2008). Clearly, this claim reveals the intensely negative representations of the Turks and how these representations are influential to the ways teachers behave toward all Turkish-speaking individuals, including children.

The second key finding is that despite negative discourses and practices toward Turkish-speaking children, there is resistance on the part of a few teachers and a school principal; this resistance is expressed through liminal performance (McKenzie 2003) such as counter-stories and counter-practices that challenge or 
temporarily suspend the 'normal/ised' identities of Turkish-speaking children. Although teacher resistances do not seem to have any major effect on transforming the structural inequalities that persist on an everyday basis (Gillborn 2008; Taylor, Gillborn and Ladson-Billings 2009) and are often veiled as formal equality for all (Vaught and Castagno 2008), it is important that the 'normal/ised' identities of Turkish-speaking children do not remain unchallenged. These (small) openings are essentially possibilities for cultivating individual and collective political consciousness and criticality against fixed and reified identities of the past (Zembylas 2008). Data in this study tell us that these openings exist because individual teachers enact their agency to invent pedagogies that challenge past identity categories. The reasons why these openings exist range from teacher individual sensitivity to the catalytic intervention of school leadership that brings important structural changes in school life.

The findings of this study are important because they demonstrate how the teachers' racialised, ethnicised and classed perceptions of a minoritised group of children intersect with larger structural, systemic issues of race, ethnicity and education in a conflict-ridden society. Previous research (e.g. see Vaught and Castagno 2008) has shown the range of social and structural components which influence the common phrase 'I don't think I'm a racist' as well as the discursive functions of self-justification and disarming criticism about accusations of racism. However, an important sociological point emanating from the use of Critical Race Theory in the present study is that while this position (i.e. 'I don't think I'm racist') exists, there is additionally the position of some teachers who admit it is their 'right' to be racist when their country is perceived to be in danger. This finding also complicates theoretical understandings of teachers' ambivalent justifications of their 
racialised, ethnicised and classed practices; contextual concerns are manifest in simultaneous claims that there should be equal opportunities for all children (see Rattansi and Phoenix 2005), yet it is rightful to be racist under some circumstances. Other studies in Cyprus on these topics seem to highlight this ambivalence in prospective Greek-Cypriot teachers (e.g. see Zembylas 2008) or Greek-Cypriot children of young age (e.g. see Spyrou 2009).

By looking through the ambivalences of teachers' constructions in these three schools, we are able to see not only what is problematic, but also to discover a window of opportunity for addressing the problematic aspects of the racialised, ethnicised and classed framework in schooling. For example, teachers' discourse on equality and fairness can be used as a point of departure to identify practices where solidarity might be possible (Anthias and Yuval-Davis 1992). Critical Race Theory provides the conceptual frame to problematize how perceptions and practices establish, assert, and reinforce power differentials and hierarchies, and how individuals draw on the resources of stereotypes to reproduce racism/nationalism/ classism. Racialised/ethnicised/classed discourses are facilitated by relevant modes of engagement and are perpetuated through the cultivation of particular practices—such as collective behaviour and school policies that contribute to the formation of inclusions/exclusions (Gillborn 2008). Unavoidably, then, it is important to analyze the modes through which such perceptions are authorized by, implied and manifest in teacher practices and school policies. Therefore, providing systemic opportunities for teachers and school staff-in conjunction with implementing equal treatment of Turkish-speaking children-to problematize exclusive practices, and considering what those practices do on Turkish-speaking children, are crucial for exploring alternative pedagogical practices and policies. 
The issue raised by some teachers that it is their right to be racist in the sociopolitical circumstances of Cyprus is arguably a far more challenging one to address. Yet, becoming aware of colour-blind views does not necessarily lead to empathy among teachers but may even result in a reinvention of racist frameworks (Vaught and Castagno 2008). This suggests that racism adapts to new ideologies and contexts (e.g. conflict in Cyprus), accommodating the discourse within a framework of racial and ethnic superiority for security, survival or other justifications. Therefore, as long as a conflict remains unresolved, it is unlikely that the multiple aspects which sustain this framework will just fade away (Bekerman, Zembylas and McGlynn 2009). Without large-scale structural transformations of the educational system of which teachers are part (e.g. new curricula and educational goals; different philosophies, pedagogical practices and educational materials; political will for social change), the fact and practice of racism/nationalism/classism will go unaltered in schools (Gillborn 2008; Zembylas 2008). These findings raise deeper issues about how to effectively challenge 'racist' teachers' perceptions and practices in conflict-ridden societies, and continue to remind those of us involved in peace and intercultural education that however difficult or improbable we are to find some perceptions, there is hardly any other choice but to look constantly for critical and hopeful alternatives. 


\section{References}

ANTHIAS, F. and YUVAL-DAVIS, N. 1992 Racialised Boundaries: Race, Nation, Gender, Colour and Class and the Anti-racist Struggle, London: Routledge.

ARCHER, L. 2003 Race, Masculinity and Schooling: Muslim Boys and Education, Buckingham: Open University Press.

ARCHER, L. and FRANCIS, B. 2005 "They never go off the rails like other ethnic groups": Teachers' constructions of British Chinese pupils' gender identities and approaches to learning' British Journal of Sociology of Education, vol. 26, no. 2 , pp. $165-182$.

BEKERMAN, Z. and MAOZ, I. 2005 'Troubles with identity: Obstacles to coexistence education in conflict ridden societies' Identity: An International Journal of Theory and Research, Vol. 5, no. 4, pp. 341-357.

BEKERMAN, Z., ZEMBYLAS, M., and MCGLYNN, C. 2009 'Working towards the de-essentialization of identity categories in conflict and pos-conflict societies: Israel, Cyprus, and Northern Ireland', Comparative Education Review, Vol. 53, no. 2, pp. 213-234.

BRYANT, R. 2004 Imagining the Modern: The Cultures of Nationalism in Cyprus, London: I. B. Tauris.

CARSPECKEN, P., and WALFORD, G. (eds) 2001 Critical Ethnography and Education, New York: Routledge.

CONNOLLY, P. 1998 Racism, Gender Identities and Young Children, London: Routledge. 
DE HAAN, M. and ELBERS, E. 2004 'Minority status and culture: Local constructions of diversity in a classroom in the Netherlands', Intercultural Education, Vol. 15, no. 4, pp. 441-453.

DELGADO, R., and STEFANCIC, J. 2001 Critical Race Theory, New York: New York University Press.

DONNELLY, C. 2004 'What price harmony? Teachers' methods of delivering an ethos of tolerance and respect for diversity in an integrated school in Northern Ireland', Educational Research, Vol. 46, no. 1, pp. 3-16.

ERICKSON, F. 1986 'Qualitative methods in research on teaching', in Michael C. Wittrock (ed), Handbook of Research on Teaching, New York: Macmillan Publishing Company, pp. 119-161.

GILLBORN, D. 2008 Racism and Education: Coincidence or Conspiracy, London: Routledge.

GILLBORN, D. and MIRZA, H. 2000 Educational Inequality: Mapping Race, Class and Gender: A Synthesis of Research Evidence, London: Office of Standards in Education.

HARRY, B. and KLINGNER, J. 2006 Why Are so Many Minority Students in Special Education? Understanding Race and Disability in Schools, New York: Teachers College Press.

JENKINS, R. 1996 Social Identity, London, Routledge.

MADISON, D. S. 2005 Critical Ethnography: Method, Ethics, Performance, Thousand Oaks: Sage.

MCGLYNN, C., ZEMBYLAS, M., BEKERMAN, Z. and GALLAGHER, T. (eds) 2009 Peace Education in Conflict and Post-conflict Societies: Comparative Perspectives, New York: Palgrave, MacMillan. 
MCKENZIE, J. 2003 Perform or else: From Discipline to Performance, New York: Routledge.

MERRIAM, S. 1998 Qualitative Research and Case Study Applications in Education, San Francisco: Jossey-Bass.

PANAYIOTOPOULOS, C. and NICOLAIDOU, M. 2007 'At a crossroads of civilizations: Multicultural education provision in Cyprus through the lens of a case study', Intercultural Education, vol. 18, no. 1, pp. 65-79.

PHOENIX, A. 1998 'Dealing with difference: The recursive and the new' Ethnic and Racial Studies, vol. 21, no. 5, pp. 859-880.

- 2002 'Mapping present inequalities to navigate future success: Racialisation and education' British Journal of Sociology of Education, vol. 23, no. 3, pp. 505515.

RATTANSI, A. and PHOENIX, A. 2005 'Rethinking youth identities: Modernist and postmodernist frameworks', Identity: An International Journal of Theory and Research, vol. 5, no. 2, pp. 97-123.

ROSS, A. 2007 'Multiple identities and education for active citizenship', British Journal of Educational Studies, vol. 55, no. 3, pp. 286-303.

SLEETER, C. and DELGADO BERNAL, D. 2002 Critical Pedagogy, Critical Race Theory and Anti-racist Education: Implications for Multicultural Education ( $2^{\text {nd }}$ ed.), San Francisco: Jossey-Bass.

SPYROU, S. 2006 'Constructing "the Turk" as an enemy: The complexity of stereotypes in children's everyday worlds', South European Society and Politics, vol. 11, no. 1, pp. 95-110.

— 2009 'Between intimacy and intolerance: Greek Cypriot children's encounters with Asian domestic workers', Childhood, vol. 16, no. 2, pp. 155-173. 
STEVENS, P. 2007 'Researching race/ethnicity and educational inequality in English secondary schools: A critical review of the research literature between 1980 and 2005', Review of Educational Research, vol. 77, no. 2, pp. 147-185.

- 2008 'Exploring pupils' perceptions of teacher racism in their context: A case study of Turkish and Belgian vocational education pupils in a Belgian school', British Journal of Sociology of Education, vol. 29, no, 2, pp. 175-187.

STRAUSS, A. and CORBIN, J. 1994 'Grounded theory methodology: An overview', In Norman Denzin and Yvonna Lincoln (eds), Handbook of Qualitative Research, Thousand Oaks, CA: Sage, pp. 273-285.

TAYLOR, E., GILLBORN, D., and LADSON-BILLINGS, G. (eds) 2009 Foundations of Critical Race Theory in Education, London: Routledge.

TRIMIKLINIOTIS, N. 2004 'Mapping discriminatory landscapes in Cyprus: Ethnic discrimination in a divided education system', The Cyprus Review, vol. 16, no. 1, pp. 53-86.

YOUDELL, D. 2006 Impossible Bodies, Impossible Selves: Exclusions and Student Subjectivities, Netherlands: Springer.

VAUGHT, S., and CASTAGNO, A. 2008 “"I don't think I'm racist”: Critical race theory, teacher attitudes, and structural racism', Race Ethnicity and Education, vol. 11 , no. 2 , pp. $95-113$.

WOODWARD, K. 2002 Understanding Identity, London: Arnold.

ZEMBYLAS, M. 2008 The Politics of Trauma in Education, New York: Palgrave, MacMillan.

— in press 'Critical discourse analysis of educational policy of multiculturalism and intercultural education policy in the Republic of Cyprus', The Cyprus Review. 
MICHALINOS ZEMBYLAS is Assistant Professor of Education in the School of Social Sciences and Humanities, Open University of Cyprus.

ADDRESS: 5 Ayiou Antoniou Str., Strovolos 2002, Nicosia, CYPRUS

Email: m.zembylas@ouc.ac.cy

Notes

1 The term Turkish-speaking is purposely used in this article in that it is more inclusive than the term Turkish Cypriots because most Roma in Cyprus speak Turkish. It is not always easy to distinguish who is ethnically Turkish Cypriot and who is Roma; therefore, the term 'Turkish-speaking' is preferred to refer to all Turkish-speaking groups. When it is important to make a distinction between Turkish Cypriots and Roma, this is explicitly stated in the text.

Various polls show that Turks, in general, are negatively viewed in Europe. Certainly negative discourse and discrimination toward Turkish-speaking children in European countries is bound to add to how they are racialised and treated in schools (Stevens 2008). As it will be shown through the data presentation, the larger context of anti-Turk sentiment in the Greek-Cypriot community is mostly grounded in the Turkish occupation of the northern part of Cyprus rather than Turkey's EU membership, and has an impact on teachers' perceptions of Turkish-speaking children.

3 Pseudonyms are used for individuals and locations to protect anonymity.

4 Transcription notation

[...] Material omitted by the author

[text] Material added by the author for the sake of clarity 